\title{
L'église de Saint-Aubin (Côte-d'Or)
}

\section{Christian Sapin et Vanessa Hontcharenko}

\section{(2) OpenEdition}

\section{Journals}

\section{Édition électronique}

URL : https://journals.openedition.org/cem/11200

DOI : $10.4000 /$ cem. 11200

ISSN : 1954-3093

Éditeur

Centre d'études médiévales Saint-Germain d'Auxerre

Édition imprimée

Date de publication : 15 août 2009

Pagination : 41-44

ISSN : 1623-5770

\section{Référence électronique}

Christian Sapin et Vanessa Hontcharenko, «L'église de Saint-Aubin (Côte-d'Or) », Bulletin du centre d'études médiévales d'Auxerre | BUCEMA [En ligne], 13 | 2009, mis en ligne le 16 septembre 2009, consulté le 22 septembre 2022. URL : http://journals.openedition.org/cem/11200 ; DOI : https:// doi.org/10.4000/cem. 11200

Ce document a été généré automatiquement le 22 septembre 2022.

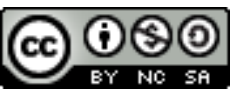

Creative Commons - Attribution - Pas d'Utilisation Commerciale - Partage dans les Mêmes Conditions 4.0 International - CC BY-NC-SA 4.0

https://creativecommons.org/licenses/by-nc-sa/4.0/ 


\title{
L'église de Saint-Aubin (Côte-d'Or)
}

\author{
Christian Sapin et Vanessa Hontcharenko
}

1 L'ancienne église de Saint-Aubin, œuvre du $\mathrm{X}^{\mathrm{e}}$ siècle, subsiste à l'ouest de l'édifice actuel. Introduite par une tour porche, elle se distingue par son chœur à deux niveaux. L'abside primitive, retrouvée lors de fouilles conduites par M. Gili en 1975, a laissé place $\mathrm{au} \mathrm{XV}^{\mathrm{e}}$ siècle à une seconde nef, plus vaste, à laquelle fut adjointe une sacristie au $\mathrm{XVI}^{\mathrm{e}}$ siècle puis un chœur au XIX ${ }^{\mathrm{e}}$ siècle.

2 Les travaux de restauration menés par l'architecte en chef des Monuments historiques É. Pallot de 2006 à 2008, suivis de près par le CEM, ont été l'occasion de nombreuses observations ${ }^{1}$. En complément, l'intervention archéologique de 2008 sur les parements extérieurs a démontré l'appartenance du mur sud de la nef, de la tour ouest et du chœur étagé à la première campagne de construction $\mathrm{du} \mathrm{X}^{\mathrm{e}}$ siècle et d'en caractériser l'appareillage. Le mur nord de la nef a été partiellement reconstruit au XIII ${ }^{\mathrm{e}}$ ou au XIV ${ }^{\mathrm{e}}$ siècle. L'ouverture rencontrée au nord-ouest est plus tardive.

3 La présente opération consistait à préciser à nouveau la fonctionnalité de l'édifice primitif et son évolution architecturale telle que l'avait proposé C. Sapin, par la pratique de sondages sur les élévations intérieures et par l'ouverture d'un sondage dans le sol du porche. Une organisation architecturale et liturgique sur deux niveaux a été mise en évidence, concentrée sur l'opposition de deux espaces privilégiés que représentent le chœur et la tour porche. Au premier étage de la tour occidentale, la mise en œuvre d'une large arcade ouverte sur la nef fait face au chœur étagé, offrant une communication visuelle entre les parties hautes des massifs ouest et est. Une telle distribution horizontale et verticale de la construction implique l'existence d'éléments de circulation. Lors de la reprise du mur nord de la nef, des corbeaux ont été ancrés dans la maçonnerie afin de soutenir une galerie de circulation rejetée à l'extérieur (cf. CEM 12). Mais en ce qui concerne les éléments de circulation contemporains de la construction du $\mathrm{X}^{\mathrm{e}}$ siècle, aucun témoignage supplémentaire n'a pu être remarqué sur les parements intérieurs. La reconstruction du mur nord, support de multiples couches de peintures murales, et la reprise intégrale de l'enduit intérieur du mur sud au $\mathrm{XVI}^{\mathrm{e}}$ siècle nous privent de tout indice quant à la présence d'éléments de circulation 
dans le volume de la nef, qui semblent toutefois vraisemblables d'après les passages étroits figurant en partie haute du chœur. Les multiples ouvertures découvertes lors des travaux répondent indirectement à ce problème de circulation. Le rez-de-chaussée de la tour-porche préserve les indices de deux larges ouvertures au nord et à l'ouest, ayant fonctionné simultanément. L'étage de la tour est également percé au nord par une ouverture plus étroite. En complément des traces d'arrachement et des reprises de maçonneries, ces passages témoignent de l'existence de structures bâties intimement liées à l'église qui justifieraient le désaxement des baies des chapelles septentrionales du chœur.

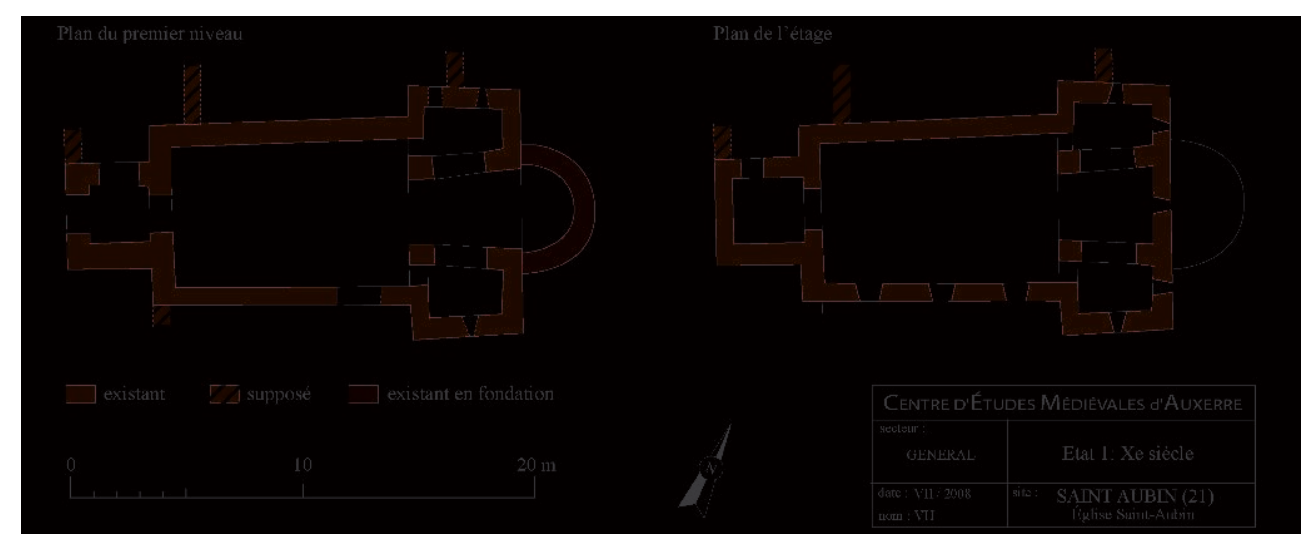

Fig. 1 - Plan de l'église de Saint-Aubin (CEM, V. Hontcharenko).

4 La reconstruction de l'édifice aux XIII ${ }^{\mathrm{e}}-\mathrm{XIV}^{\mathrm{e}}$ siècles, qui voit l'intégration d'une baie à coussiège dans le mur nord de la nef, préserve la distribution architecturale des lieux. Ces travaux font suite à une phase d'incendie et de destruction, dont les traces ont été repérées en fouille et en surface des maçonneries. Ce n'est qu'entre le $\mathrm{XIV}^{\mathrm{e}}$ et le $\mathrm{XVI}^{\mathrm{e}}$ siècle que l'organisation intérieure des bâtiments est modifiée par la création de nouveaux accès et le bouchage des ouvertures de la nef, lequel amène l'isolement de l'étage de la tour occidentale.

5 Malgré les dimensions modestes de l'édifice primitif, l'opposition de deux massifs étagés et la présupposition de bâtiments liés révèlent une construction relativement coûteuse ayant impliqué des moyens conséquents. Les archives témoignent de donations pour des messes dès le début du XIII siècle, mais aucune famille ou groupe politique ou religieux ne se distingue. L'hypothèse ducale d'après la donation du patronage de ladite église au chapitre Notre-Dame de Beaune par le duc Henri - reste la seule envisagée, au moins pour le premier état. 


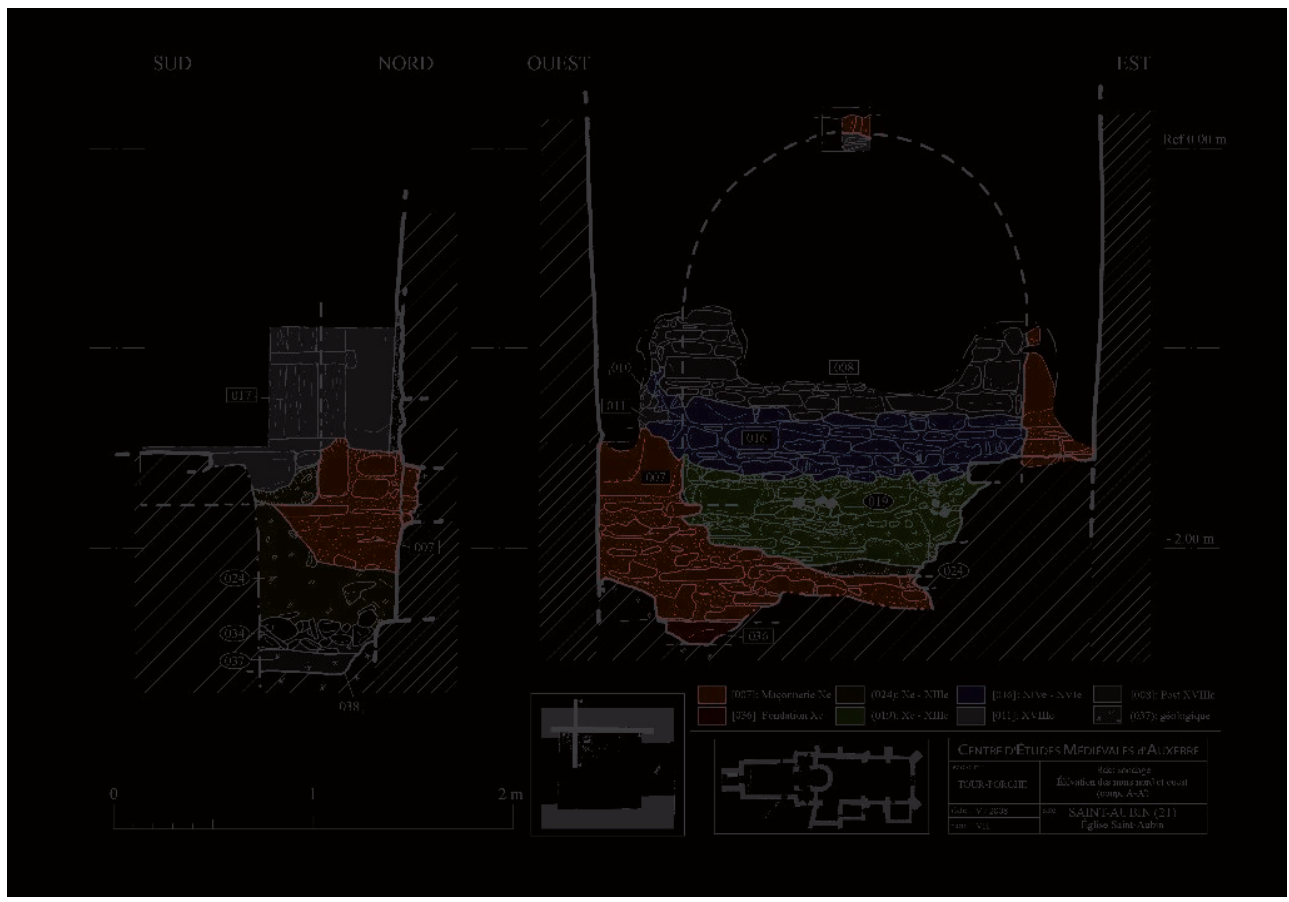

Fig. 2 - Église de Saint-Aubin, tour-porche (CEM, V. Hontcharenko).

\section{NOTES}

1. Voir les travaux de J. Mercier dans le Bulletin du Centre d'études médiévales d'Auxerre, 12 (2008), p. 45 (http://cem.revues.org/document5952.html).

\section{INDEX}

Index géographique : France/Saint-Aubin Mots-clés : église 